\title{
On China's College Entrance Examination System and Its Future Orientation
}

\author{
Huanhuan Xiong* \\ School of Mathematics, \\ Zhejiang Ocean University \\ Zhejiang, 316022, China \\ xionghuanhuan1995@163.com
}

\author{
Hailiang Zhang \\ School of Mathematics \\ Zhejiang Ocean University \\ Zhejiang, 316022, China \\ hlzhang88wy@163.com
}

\author{
Weixing Cao \\ School of Civil Engineering \\ Zhejiang Ocean University \\ Zhejiang, 316022, China \\ 373789910@qq.com,
}

\begin{abstract}
The national college entrance examination, as an important and time-honored tool for selecting the distinguished personal, has facilitated one after another group of students to enter into the institutes of higher learning, thus bringing out excellent person to contribute to the modernization process of China. However, the disadvantages of the present college entrance examination cannot afford to be ignored. Currently, while serving the interests of part students, the current examination system is also denying part of the students to bring out their talents into full play. This paper first reform and changes of China's college entrance examination system are discussed; secondly, this article focuses on the advantages and disadvantages of the current examination system; finally, this paper will explore the entrance of our future.
\end{abstract}

Keywords-College entrance examination system, Future orientation, Advantage and disadvantage

\section{INTRODUCTION}

The college entrance examination is of great concern to our Chinese people and even people across the world that cares about China's development since most of us have experienced it by ourselves or have focused on it. For those students born in an ordinary family, this examination may play a decisive role in their career or later in life.[1-3] Since the recovery of the national entrance examination in 1980s, every year thousands of students crowding into the examination hall and leaving behind them countless parents waiting with anxiety is nothing strange.

In the college entrance examination under the background, the advantages and disadvantages of the existing examination system also should be paid more attention to, which is widely concerned by social and educational workers. Featured by fierce competition, high risk and high stake, the national entrance examination is most influential exam in China evolving a large preparation of Chinese people, including national leaders, ordinary, etc.. Among the 20 questions inviting suggestions from the public in the outline of the long term development of national education, the possibility and the necessity of the division of arts and sciences come out on the top of the list of concern, which is indeed the concern over division of arts and science in college entrance examination. Under such circumstances it is of great significance to discuss about the current national entrance examination and its future development trend.[4-7]

This examination is a prerequisite for entrance into almost all higher education institutions at the undergraduate level. It is usually taken by students in their last year of senior high school, although there has been no age restriction since 2001.The exams last about 9 hours over a period of 2 days, depending on the Chinese province. Chinese literature, Mathematics, and English language (in most provinces) are required for all students. Students choose either one of two academic areas, Humanities or Natural Sciences. In 2006, a record high of 9.5 million people applied for tertiary education entry in China. Of these, 8.8 million $(93 \%)$ are scheduled to take the national entrance exam and 27,600 (0.28\%) have been exempted from standardized exams due to exceptional or special talent. Everyone else (700,000 students) will take other standardized entrance exams, such as those designed for adult education students. The overall mark received by the student is generally a weighted sum of their subject marks. The maximum possible mark varies widely from year to year and also varies from province to province.

\section{CHANGES OF COLLEGE ENTRANCE EXAMINATION SYSTEM IN CHINA}

Since the recovery of the college entrance examination in China, tremendous changes and adjustment has taken place in china's exam system over the last 30 years and it is on the way to perfecting and improving itself. To study the advantages and disadvantages of China's education system, we should first look at the reform and transformation of China's college entrance exam system. 


\section{A. The establishment and reform of college entrance examination}

Since the founding of the People's Republic of china, institutions of higher education enrollment has great changes and adjustment. Separate enrollment is carried forward in 1949 until the implementation of the joint enrollment in colleges and universities in the same region in 1950. In 1951, the unified enrollment of the greater administrative areas begins to come into being across the country, which means the end of university's autonomous enrollment system.

Instead of receiving applause from the public, the unified enrollment indeed policy has received a lot of negative response since in their perspective this kind of college entrance examination system is a regardless of individuals' personality, age, nationality, geographical location etc. and the students are denied to develop their talents. The debate upon the elimination of the college entrance examination system has been a continuous existence until the breaking out of the Cultural Revolution.

In 1990s, the abolish of the system of unified college entrance examination again became the focus of the public and all the parties concerned argued that selecting distinguished personal is of great significance for the ruling of a great nation. However, as for the college entrance examination system, those people insisting the reserve of the enrollment system claimed that under the current circumstances the unified college entrance examination is still a wise choice for the selecting of talents. Furthermore, they pointed out that an effective method must be put forward to tackle the disadvantages of the current system. In their point of view, to abolish the educational system is much more devastating than to reform it. Those people who insist the abolishment of the system argue that the fundamental reason attributing to the examination- oriented education system is the national college entrance examination. Characterized by outdated content, lacking of creativity, single form, fallacy of composition, the examination system discourages students' creativity and simply turned them into test machine, thus exerting a negative impact on children's development. These people hold the view that the seemly fair system is not fair at all and will not help to distinct professionals.

Since the beginning of the twenty-first century, the reform of the education system of our country has experienced great development. 86 universities have carried out independent recruitment what is worthwhile to mention is that Fudan University and Shanghai Jiao Tong University begun to recruit student independently under the great banner of quality education in 2006. According to these two universities, interview during the enrollment process is intended to lay a solid foundation for the development of quality education and render student a platform for the display of talent.

The reform of the national college entrance examination system still remains a long and uphill journey. Based on international and realty angle, the fairness of education can find evidence in many areas, including the college entrance examination form, content, and matriculation. Though different countries or regions may have different have different situations, their idea of and pursue for fair opportunities on higher education are basically the same. In china, there still exists vast unfairness in the national entrance examination, which has constituted a social hazard that should not be ignored. The national college entrance examination reform thus should pay more attention to fairness, though it is impossible to find a perfect reform proposal that can satisfy all kinds of fair needs and all parties' benefit appeals.

\section{B. The current practice}

National Higher Education Entrance Examination is not uniform across the country, but administered uniformly within each province of China or each direct-controlled municipality. The National Higher Education Entrance Examination is graded variously across the country. It is arranged at the end of the spring semester and secondary school graduates across the country take the examination simultaneously over a three-day period. Prior to 2003, the examination was held in July, but has since been moved to the month of June. This move was made in consideration of the adverse effects of hot weather on students living in southern China and possible flooding during the rainy season in July.

In different places and across different time in history, students were required to apply for their intended university or college prior to the exam, after the exam, or more recently, after they learned of their scores, by filling a list of ordered preferences. The application list is classified into several tiers (including at least early admissions, key universities, regular universities, vocational colleges), each of which can contain around 4-6 intended choices in institution and program, though typically an institution or program would only admit students who apply to it as their first choice in each tier. In some places, students are allowed to apply for different tiers at different times.

The exam is administered for two or three days. Three subjects are mandatory everywhere: Chinese, Mathematics, and a foreign language-usually English, but this may also be substituted by Japanese, Russian or French. The other six standard subjects are three sciences: Physics, Chemistry, Biology, and three humanities: History, Geography, and Political Education. Applicants to science/engineering or art/humanities programs typically take one to three from the respective category. Since the 2000s, an integrated test, science integrated test, humanities integrated test or wider integrated test has been introduced in some places. This integrated test may or may not be considered during admission. In addition, some special regional subjects are required or optional in some places. Currently, the actual requirement varies from province to province.

The subjects tested in the National Higher Education Entrance Examination have changed over time. Traditionally, students would undertake either a set of "arts" subjects or a set of "science" subjects, with some shared compulsory subjects. The subjects taken in the Examination affected the degree or career paths open to the student. In recent years, different provinces have included different subjects in the Examination, or implemented flexible systems for selecting the subjects to be tested, resulting in a number of different systems. 


\section{THE ADVANTAGES AND DISADVANTAGES OF COLLEGE ENTRANCE EXAMINATION SYSTEM}

The reform of the national college has undergone more 30 years of changes and adjustments and is still adopted across the country and it will certainly experience more changes and reforms to better serve the interest of the youth and the Chinese people as a whole in the future. Under such circumstance it is of great importance to look at the advantages and disadvantages of college entrance examination system in china.

\section{A. The advantages of college entrance examination system}

The college entrance examination system can achieve the fair and scientific selection of talents and is conducive to the cultivation of their character. Moreover, it renders a tremendous opportunity for students living in rural areas and laid a solid foundation for tertiary education. This part will explore further about the advantages of college entrance examination system by taking mathematics as an example.

The test of Mathematics is intended to cultivate students' spatial imagination ability, abstract generalization ability, reasoning ability, computing ability, data processing capacity and their awareness of creation and application, in which the awareness of creation and application is the ultimate goal. The awareness of creation means that we must develop the ability to distinct the problem and then come out ways to save the people through the teaching method as well as the thinking mode we have learned. Rational thinking is the ultimate level of critical thinking and the analysis, imagination, abstract thinking, generalization and prove of mathematical problem is crucial to the solvent of the problem.

Besides, personality comprises personal outlook towards value and life. In the test of Mathematics, students are required to develop a mathematic perspective and scientific outlook on Mathematics, thus developing a rational thinking mode and appreciating the aesthetic beauty of Mathematics.

During the college entrance examination, the students are expected to overcome the mental as well as physical barriers to solve the problems with full confidence. In the course of their, their personality, all kinds abilities are tested, through which man with scientific Mathematics may be chose.

\section{B. The disadvantages of college entrance examination system}

While boasting substantial advantages, college entrance examination system also have a Lot disadvantages. Regional discrimination in student's enrollment has already become a public concern. An admission quota allocation policy based on geographical location often practices a local protection policy, which means relatively more quotas, is allocated to the local province. Under such circumstances, the native students may attend the universities or colleges at a lower grade. This is particular true for universities in cities like Beijing. Large proportion of students want to graduate into institution of higher learning like Tongue University and Peking University, but only few people could have access to it since they implement a local protection policy to enroll more Peking people.
The present college entrance examination system to certain degree is not conducive to the development of students' creativity and not in consistent with the need of the information era. Nearly millions of Chinese students undergo a fierce competition of the entrance examination to college every year. After that some of them get an offer of college while others do not. For most Chinese student, the college entrance examination could be once-a- life chance to change their life. The college entrance examination has social and economic functions, it is necessary to make it keep up with times and actively reform, but also add some new forms of testing one's true ability and guarantee provincial justice.

\section{1) Independent proposition}

Regional imbalance of social and economic development has resulted in disparity in education levels across China, which gives rise to provincial proposition. However, provincial governments have to increase budget on education in order to offset the declining credibility of the exam caused by lack of experienced proposition experts and management personnel, which will, more or less, cause a repetitive investment in human resources, finance or material. Moreover, independent proposition covers regional discrimination generated by huge disparity of cut off scores between different provinces.

\section{2) Academic segregation}

Chinese students are required to choose either Socia Sciences (political science, geography, and history) or Natural Sciences (physics, chemistry, and biology). This happens particularly at the end of the first year of high school, when students were mostly 15-16 years old. Once they make their decisions at such a young age, they have to start prepare for the subject tests, and no longer take classes of, or explore the other 3 subjects. The decision made at such a young age decides which college entrance test they are going to take at the age of 18 , as well as their college majors and future career path. This testing policy limits the student's academic interests and potential, and forces students to make decisions of their life at a particularly young age.

\section{3) Psychological pressure}

Because College Entrance Examination is one of the most influential examinations in China and the fact that students can only take the test once a year, both teachers and students undergo tremendous pressure in preparing for and taking the exam. For teachers, because the society focuses on the rate of admission into universities, teachers have to pay more attention to each student's ability to take the exam. Because of this, teachers would like to give students more and more practice for exams. This teaching methodology, colloquially referred to as "cramming", involves students memorizing large volumes of information fed to them by teachers and undertaking many practice exercises in order to optimize exam writing ability. One of the disadvantages of this method is the lack of focus on teaching critical thinking and ignoring students' emotions, values and personalities. Many examinees suffer from severe nervousness during the test. In some cases, examinees may faint in the examination room.

Further and deeper stemming criticisms have been leveled that the testing system is the "most pressure packed examination in the world." Behaviors surrounding the testing 
period have been extreme under some reports, with doctors in Tianjin purportedly prescribing birth control pills to female students whose parents wanted to ensure the girls were not menstruating at the time of examination. Testing pressure, for some critics, has been linked to fainting, increased dropout rates, and even increasing rates of teenage clinical depression and suicide in China.

\section{4) Regional discrimination}

A university usually sets a fixed admission quota for each province, with a higher number of students coming from its home province. As the advanced educational resources (number and quality of universities) are distributed unevenly across China, it is argued that people are being discriminated against during the admission process based on their geographic region. For example, compared to Beijing, Jiangxi province has fewer universities per capita. Therefore, Jiangxi usually receives fewer admission quotas compared with Beijing, which makes a significantly higher position among applicants necessary for a Jiangxi candidate to be admitted by the same university than his Beijing counterpart. The unequal admission schemes for different provinces and regions might intensify competition among examinees from provinces with fewer advanced education resources. For example, Beijing University planned to admit 1800 science students from Beijing (with 80,000 candidates in total), but only 38 from Shandong (with 660,000 candidates in total). This is not similar to the practice of regional universities in other countries which receive subsidies from regional governments in addition to or in place of those received from central governments, as universities in China largely depend on state budget rather than local budget. However, this regionally preferential policy does provide subsidies to students from under-developed regions that enjoy limited educational resources, such as Tibet and Xinjiang.

The regional discrimination can be proved by the disparities between ratios of a province's enrollment of students to the total number of candidate students of the province. In 2010, acceptance rate for students from Beijing, Shanghai, Shandong and Henan who applied for universities of the first-ranking category were $20.1 \%, 18 \%, 7.1 \%$ and $3.5 \%$ respectively. High acceptance rates are likely to appear in the most and least developed cities and provinces, such as Beijing, Shanghai or Qinghai. In contrast, acceptance rates remain relatively equal among provinces of the average developmental level. In recent years, varied admission standards have led some families to relocate for the sole purpose of advancing their children's chances of entering university.

In addition, regional discrimination is not only restricted to the ratio for admission. This is best illustrated with an example of the Hubei Province, where students' exam scores have been higher than other provinces for a long time. A score for a Hubei student to just reach the admission cut-off line for a key university may be enough for a student from another province to be admitted by a much better university, and even enough for a Beijing student to be admitted by top universities like Tsinghua University and Peking University.

\section{THE FUTURE ORIENTATION}

The national college entrance examination is associated with the distribution of quality educational resources and also includes the redistribution of social benefits. Reform of the national college entrance examination thus should not only represent the orientation of Chinese advanced culture, but also the fundamental interest of Chinese people. Moreover, every education must be prevented from deny the opportunities of the students from underdeveloped regions to have access to higher learning. Instead of designing an individual recruitment in every institution or a simple copy of the US college enrollment mode, the fundamental goal of China's college entrance examination system id to reform our own educational system according to our specific circumstances. The direction of china's college entrance examination system reform is seeking for diversification. As you how to improve the system, we should make decisions based on weighing advantages and disadvantages. Conducting a new reform policy should be based on carefully debated public opinions and on the pilot studies at the selected institution.

The combination of unity and diversity should always be the guiding principle for China's college entrance examination system. First the examination of core subjects must be made compulsory for everyone. The national college entrance examination can not only bridge the gap between secondary education and tertiary education but also an important convergence point for the connection between higher education and the sociality as a whole. The unified examination of the core subject can ensure the fair and justice of the exam, which is a vivid expression of the principle that socialist society takes responsibility for the interests of all the people and thus maintain the social stability.

One the basis of unity, we must seek for multiple ways to recruit students who has talents in other field. The arrangement of the college entrance examination must take full consideration of students' talent and personality. Diversified examination must be perused so as to promote the development of secondary education and tertiary education.

With the mature of social economy, china's market economy status is established and the class differentiation in China is becoming more acute. In order to meet the specific demand of different classes, we must pursue a combination of unity and diversity.

\section{ACKNOWLEDGEMENT}

2016 University Students Technology Innovation Project Proposal of Zhejiang Ocean University (Xinmiao Talents Program).

\section{REFERENCES}

[1] Liu Peng, Xian jun Tan, Fang Xie. Rethinking the Way Out for College English Teaching-After China's Reform in National College Entrance Exam in English[J]. Journal of Language Teaching and Research, 2014.(In Chinese)

[2] Haifeng Liu. Reform of the College Entrance Examination [J]. Chinese Education \& Society, 2013.(In Chinese) 
[3] Valli, Rebecca. Scandal Threatens China's College Entrance Exam[J]. Voice of America News / FIND, 2014.

[4] Houxiong Wang. A Commentary on China's New Curriculum and the Programs to Design Subjects for the College Entrance Examination [J]. Chinese Education \& Society, 2013.(In Chinese)

[5] Claudia Trevisan (2009). Omair Vestibular Do Mundo, Terca-Feira, 27 de Outubre de 2009.(In Chinese)
[6] Guanghai Wang, Fen Ren, Zhijun Liu, Guangxing Xu, Fan Jiang, Elizabeth Skora, Daniel S. Lewin. Sleep Patterns and Academic Performance During Preparation for College Entrance Exam in Chinese Adolescents[J]. J School Health, 2016.(In Chinese)

[7] Zheng Ruoling. On the Rationality of the College Entrance Examination [J]. Chinese Education \& Society, 2010.(In Chinese) 